\section{Jean Ziegler e a geopolítica da fome}

Jean Ziegler and hunger geopolitics

Katia Hale*

Destruição em massa - geopolítica da fome é o mais novo livro de Jean Ziegler lançado no Brasil, traduzido e prefaciado pelo professor José Paulo Netto. Embasado em experiências durante seu trabalho na relatoria do direito à alimentação da ONU entre 2000 e 2008, como sua atuação no Conselho de Direitos Humanos da mesma instituição, o autor discorre sobre a geopolítica da fome e a devastação causada pelo fenômeno. Contumaz estudioso, pesquisador e militante no combate à fome, nos traz à lembrança Josué de Castro, intelectual e militante brasileiro cujo pensamento é resgatado na obra em questão. No livro, dividido em seis partes, o autor analisa, denuncia e sugere alternativas para a destruição em massa pela fome.

$\mathrm{Na}$ primeira parte, o pensador suíço descreve a extensão da destruição em massa pela fome, culminando na subalimentação de homens, mulheres e crianças em todo o mundo. Na geopolítica da fome, os países do

* Assistente social, professora no curso de Serviço Social das Faculdades Metropolitanas Unidas (FMU), mestre em Serviço Social pelo programa de ensino pós-graduado em Serviço Social na PUC-SP, São Paulo (SP), Brasil, doutoranda no mesmo programa.E-mail: katiahale@gmail.com. hemisfério sul são os perdedores. Exemplo gritante são as mais de 500 mil mulheres que morrem anualmente ao realizarem o parto, a maioria pela falta prolongada de alimentos durante a gravidez. As sobreviventes não têm como alimentar seus filhos, nem condições para comprar alimentos que substituam o leite materno.

A contagem de famélicos realizada pela $\mathrm{FAO} / \mathrm{ONU}$ apresenta falhas, segundo estudiosos citados pelo autor. Bernard Maire e Francis Delpeuch são dois dos autores que apresentam críticas pertinentes quanto ao modelo de cálculo utilizado pela FAO/ONU. As estatísticas determinam os déficits em termos de calorias (proteínas, glicídios e lipídios), ou seja, os alimentos que fornecem energia, não considerando a deficiência da população no que se refere aos micronutrientes (carência de vitaminas, minerais e oligoelementos). Nessa direção, afirma o autor, de Destruição em massa geopolítica da fome: "a ausência de iodo, ferro, vitaminas A e C, entre outros, são indispensáveis à saúde e sua ausência gera cegueira, mutilações e a morte de milhões de pessoas". Outra crítica que procede em relação ao método é a confiabilidade dos dados fornecidos pelos Estados nacionais, já que incontáveis países do hemisfério sul não dispõem de método científico adequado para a contagem da população, sendo que as vítimas da fome, em sua maioria, lá se encontram. Acrescentamos que os dados oficiais de países que possuem caminhos para verificar a realidade são questionáveis, já que o aferimento de dados verdadeiros a respeito dessa realidade compromete governos, 
eleições e o repasse de verba por organismos internacionais. A ideologia tecnocrata do Estado burguês transforma a realidade em quantidade, não fazendo análises qualitativas, nem as mediações necessárias para compreensão da realidade. Dessa forma, dependendo do momento e dos interesses de cada Estado, os números oscilam para mais ou para menos. Em relação ao número de famintos fica a questão: quantos são os que sofrem com a fome subalimentar e a má alimentação (fome de micronutrientes) em todo o mundo?

A maioria dos seres humanos que não têm o suficiente para comer, segundo o autor, localiza-se nas comunidades rurais pobres dos países do hemisfério sul. É histórica a condição de miséria e fome dos camponeses e, atualmente, eles correspondem a aproximadamente 500 milhões vivendo em condição de extrema pobreza. A miséria de agricultores, criadores e pescadores se apresenta por três razões: frequentemente são trabalhadores migrantes arrendatários, superexplorados pelos proprietários, ou ainda, a dimensão e a qualidade da terra são insuficientes para alimentar a sua família. Para superar o problema, o Banco Mundial sugere a reforma agrária assistida, ou seja, o latifundiário abre mão de parte de suas terras, mas o trabalhador rural deve comprar a sua parcela com o financiamento do referido banco, proposta que se constitui numa "piada de mau gosto".

A violência é endêmica em alguns países. Não bastasse a destruição pela fome do homem do campo, na tentativa de lutar por um pedaço de terra, ele é morto sem que qualquer medida seja tomada. Esses trabalhadores estão, de forma planejada, invisíveis aos olhos do Estado e das elites nacionais. Exemplifica o autor com o número de mortos na Guatemala em 2005: 4.793 assassinatos. Tanto na América Central quanto na América do Sul, na Índia, no Paquistão e em Bangladesh, a luta para se manter num pedaço de chão ou para saciar a fome é motivo de chacinas e torturas: "A dor do vazio no estômago é calada com um tiro à queima-roupa".

Na geopolítica da fome, o hemisfério sul foi o mais prejudicado na sequência da crise econômica de 2008. Falências, fechamento de fábricas e ondas de desemprego. Menores investimentos em políticas sociais e injeção de recursos para "socorrer banqueiros delinquentes", na apropriada expressão usada por Ziegler. Em 2009, o Banco Mundial anunciou: o número de pessoas vivendo na extrema pobreza aumentaria em mais 89 milhões, e a quantidade de pobres cresceria em mais 120 milhões.

O despertar das consciências é o tema da segunda parte da obra. Nela é demonstrada a fome como fatalidade sob a errônea visão de Malthus, um mal necessário propalado em 1798 e que ainda se mantém. Resgata o pensamento de Josué de Castro, afirmando que fora quebrado, logo após a Segunda Guerra Mundial, o tabu da fome. Fez-se ouvir o grito dos famintos na luta do médico pernambucano, declara. Lançando mão da geografia humana, Castro localiza a fome como problema provocado pelo homem, não existindo obstáculos "naturais" para se acabar com ela. O progresso desejado 
naquele período da história dependeria somente da intervenção planejada do Estado e da cooperação dos "homens de boa vontade". As análises de Castro encontram eco na Europa devastada do pós-guerra, no entanto, a ONU e, posteriormente, a FAO, fundadas no período, não apresentaram os resultados esperados. Atualmente, denuncia o autor, mais de $40 \%$ dos homens, mulheres e crianças do Recife vivem nas sórdidas favelas que margeiam o Capibaribe. Mais de 1 milhão de pessoas moram ali, sem fossas sépticas, esgotos, água corrente e eletricidade. "O homem caranguejo continua sobrevivendo."

Na terceira parte da obra, o sociólogo em tela denuncia os grupos econômicos do setor agrícola. As duzentas maiores empresas que controlam cerca de um quarto da produção mundial com lucros astronômicos dominam não apenas a formação dos preços e o comércio de alimentos, mas os setores essenciais da agroindústria, quais sejam: sementes, adubos, pesticidas, estocagem, transportes etc. Entre as dez sociedades que controlam um terço do mercado de sementes estão a Aventis, a Monsanto, a Pioneer e a Syngenta, setores que movimentam aproximadamente 23 bilhões de dólares por ano e $80 \%$ do mercado mundial de pesticidas, gerando um volume estimado em 28 bilhões de dólares. A Cargill está entre as dez sociedades que controlam o mercado varejista em todo o mundo, $57 \%$ das vendas e $37 \%$ das receitas das cem maiores sociedades fabricantes de produtos alimentícios e de bebidas. Somente seis empresas detêm $77 \%$ do mercado de adubos: Bayer, Syngenta, Basf, Cargill, DuPont e Monsanto. É comum as sociedades transcontinentais argumentarem que a fome é uma tragédia cuja responsabilidade é da produtividade insuficiente da agricultura mundial. $\mathrm{O}$ discurso se dirige a incrementar a produtividade por meio da industrialização levada ao limite, afirma o autor, com investimento de capital e de novas tecnologias, o que equivale inserir as sementes transgênicas na produção, assim como os pesticidas, eliminando a "improdutiva" agricultura familiar e de víveres e seguindo a liberalização o mais completa possível do mercado mundial. Nesse sentido, afirma que "há mais de duas décadas as privatizações, a liberalização dos movimentos das mercadorias, serviços, capitais e patentes, avançaram assombrosamente". Os Estados pobres do Sul perderam sua soberania, as fronteiras desapareceram e as políticas públicas foram privatizadas. Eis o neoliberalismo orquestrado pela OMC, pelo FMI e pelo Banco Mundial, com total apoio dos Estados. Resultado: desemprego, aumento das vítimas da subalimentação e da fome.

A ruína do Programa de Alimentação Mundial (PAM) e a impotência da FAO é assunto da quarta parte do livro. O PAM tem como missão levar ajuda humanitária de urgência, e em 2010 contava com 90 milhões de famintos em sua lista. Os Estados Unidos forneciam aproximadamente $60 \%$ das contribuições do PAM, porém, as doações em espécie reduziram-se quase $80 \%$ “em função da produção em larguíssima escala de agrocarburantes, atividade sustentada por bilhões de dólares de subsídios públicos". Aponta nessa observação o ciclo perverso e contraditório do qual depende a missão do 
PAM para sua realização. Inegável a necessidade do trabalho desenvolvido pelo PAM, mas observa-se que o programa alimenta seres humanos vivendo em países ou regiões que sofreram catástrofes que poderiam ser evitadas. Ziegler dirige críticas a FAO/ONU, mas defende sua importância e a forma como operava quando fundada. Certo é que as ambiciosas atribuições da FAO nunca foram levadas a cabo. Se as sociedades transnacionais privadas se posicionam contra a FAO hoje, também no passado o capitalismo monopolista não permitiu que a instituição cumprisse seu papel. No discurso de despedida da FAO, Josué de Castro, desiludido com o que se poderia chamar de "indústria da fome", denunciou o complô dos países mais ricos contra os mais pobres e confessou a sua decepção frente à inoperância daquele organismo.

O autor discorre sobre os abutres do "ouro verde" na quinta parte do livro, afirmando ser falso o argumento das sociedades transcontinentais, produtoras de agrocarburante, de que a energia vegetal seria a arma milagrosa contra a degradação do clima. Ele nos alerta: se cerca de 500 milhões de hectares de terras aráveis africanas têm seu solo degradado, se a destruição do ecossistema e a degradação da zona agrícola em todo o mundo arrastam os emigrantes do meio ambiente para as favelas das grandes metrópoles, os produtores de agrocarburantes são os responsáveis. Tal produção demanda água, causando ainda maiores prejuízos aos que sofriam com falta de água potável, energia e a utilização de pesticidas, que contaminam rios e matam crianças em todo o mundo. É o presidente da Nestlé quem diz: "Com os biocarburantes, jogamos na pobreza mais extrema centenas de milhares de seres humanos". Os mais poderosos produtores de biocarburantes do mundo são de origem norte-americana.

É dedicada atenção à maldição da cana-de-açúcar, tomando como exemplo o Brasil, não sem motivos. No papel de relator especial sobre o direito à alimentação, Ziegler combateu o Proálcool e, na ocasião, o então ministro Vannuchi e o presidente Lula usaram argumentos de que a cana não era comestível e que, ao contrário dos Estados Unidos, os brasileiros não queimam milho e trigo. Hipocrisia. A implementação do Proálcool tem transformado a geografia agrária, a começar pela concentração de terras. Publicação da Rede Social de Justiça e Direitos Humanos de março/2012 revela que $45 \%$ do etanol produzido em escala mundial sai do Brasil. Das 435 usinas instaladas no país, a corporação Raízen, formada a partir da fusão Cosan-Shell, é a maior produtora de etanol e uma das cinco maiores empresas que aqui operam. As empresas têm acesso privilegiado a créditos e diversas formas de subsídios estatais. A insegurança alimentar na qual vive grande parte da população brasileira, afirma o autor, tem como responsável o Proálcool. O autor conclui afirmando que as práticas da escravidão persistem e que as crianças subalimentadas do Vale do Capibaribe e os desdentados cortadores de cana não têm qualquer chance de vencer o poderoso bioetanol. A violenta recolonização se estende a países da Ásia, América Latina e África, e para a aquisição de terras, os 
monopólios contam com financiamento de bancos públicos.

Os especuladores e a forma como operam é o tema da sexta e última parte do livro. É recente a migração dos especuladores que operavam no mercado financeiro para o mercado de matérias-primas, especialmente o agroalimentar, que inclui a especulação do preço dos alimentos e da terra arável. No jogo do aumento dos preços dos alimentos, o arroz, o milho e o trigo, alimentos de base, milhares de pessoas são atiradas na fome, como ocorrido em 2008, durante a crise econômica. A exploração dos preços em 2011 também colocou na situação de fome 44 milhões de crianças, mulheres e homens. Não haveria crise alimentar sem especulação, declara Olivier Shutter, sucessor de Ziegler no cargo de relator especial das Nações Unidas sobre a alimentação. Marc Roche, citado pelo autor, associa o combate contra a especulação e a luta contra os paraísos fiscais. O autor denuncia a Suíça, apontando que $27 \%$ de todos os patrimônios offshore do mundo são geridos naquele país. Os especuladores, após a crise alimentar de 2008 e 2011, avançaram em direção à compra de terras, fazendo crescer de modo acelerado tais investimentos. $\mathrm{O}$ autor revela indicadores de açambarcamento de terras no hemisfério sul do globo, evidenciando o continente africano, que, em 2010, vendeu ou arrendou 41 milhões de hectares de terras aráveis com o envolvimento, para tanto, dos bancos e fundos de investimentos suíços. Tais investidores têm como parceiro a Cosan, mencionada anteriormente. Uma das subsidiárias da Cosan, Radar Propriedades Agrícolas, está voltada para o mercado imobiliário rural, e seu objetivo é adquirir imóveis potencialmente valorizáveis. Eles compram terras e, posteriormente, arrendam ou utilizam para própria produção, operando, dessa forma, grande especulação e aumento no preço da propriedade. Controlam grandes áreas agricultáveis, haja vista seu modelo de produção. Além da cana-de-açúcar, controlam propriedades destinadas ao cultivo de soja, milho e eucalipto. A consequência social última é a miséria e a fome. "Especulando a terra, especulam com a morte." O autor destaca ainda o Banco Mundial como um dos cúmplices dessa tragédia: "O Banco Mundial, de fato, financia o roubo de terras aráveis na África, na Ásia e na América Latina". E acrescenta: "[...] tem o peso do Evangelho no Conselho de Direitos do Homem das Nações Unidas".

A análise realizada pelo autor para a destruição em massa pela fome revela inúmeros e verdadeiros determinantes, mas a porta de saída para sua superação não se encontra nos instrumentos da democracia política, não se encontra na vontade política do Estado, como quer crer o autor. Infelizmente, o discurso que se generalizou após a queda do Muro de Berlim e o fracasso da experiência soviética - entendido como a impossibilidade do socialismo real e da inviabilidade prática do comunismo - caminha na mesma esteira. É comum, inclusive entre grupos de esquerda, a defesa de injetar democracia no capitalismo e de compatibilizar a teoria de Marx à defesa dos direitos humanos, acreditando que serão garantidos pelo Estado. Tanto assim, que qualquer crítica aos direitos humanos soa como uma 
heresia totalitária. Dessa forma solucionam um falso problema, que só nasceria da desconsideração do sentido específico da critica de Marx da política, em geral e dos direitos humanos em particular. $\mathrm{O}$ direito, em Marx, não possui uma história própria, não se fundamenta em uma vontade livre. Ao contrário, está enraizado nas relações materiais de produção, mais especificamente nas relações de propriedade privada dos meios de produção. Esse nos parece ser o limite da crítica social: o Estado perdeu seu caráter de classe, e o problema central do capitalismo deixa de ser ele próprio e suas contradições, voltando-se para o problema das grandes corporações e de sua apropriação do espaço político dos centros de decisão, como que, se exterminadas, avançaríamos rumo a um capitalismo humanizado, o que por si só é uma contradição.

Entendemos, dessa forma, que o texto de Jean Ziegler é uma obra de referência para as ciências sociais e áreas afins e, certamente, deve fazer parte da biblioteca contemporânea dos estudos sociais sobre o fenômeno da fome no Brasil e no mundo.

Recebido em: 8/9/2014

Aprovado em: 9/3/2015

\section{Referências bibliográficas}

ZIEGLER, Jean. Destruição em massa: geopolítica da fome. São Paulo: Cortez, 2013.

XAVIER, Carlos V.; PITTA, Fábio T.; MENDONÇA, Maria Luisa. Monopólio da produção de Etanol no Brasil: a fusão CosanShell. Publicação da Rede Social de Justiça e Direitos Humanos. São Paulo: Outras Expressões, 2012. 